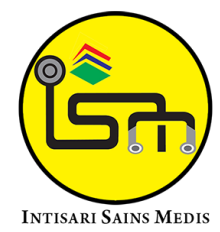

Published by Intisari Sains Medis

\section{Karakteristik malnutrisi rumah sakit pada pasien anak di RSUP Sanglah, Bali, Indonesia}

\author{
Hanzelina ${ }^{1 *}$, I Gusti Lanang Sidiartha ${ }^{1}$, I Gusti Ayu Putu Eka Pratiwi ${ }^{1}$
}

'Departemen IImu Kesehatan Anak, Fakultas Kedokteran, Universitas Udayana, RSUP Sanglah, Bali, Indonesia;

\footnotetext{
*Korespondensi:

Hanzelina;

Departemen IImu Kesehatan Anak, Fakultas Kedokteran, Universitas Udayana, RSUP Sanglah, Bali, Indonesia;

hanzel2gretel@gmail.com
}

Diterima: 05-07-2021

Disetujui: 20-08-2021

Diterbitkan: 31-08-2021

\title{
ABSTRACT
}

Background: Hospital Malnutrition (HM) is malnutrition diagnosed while being treated at the hospital either when admitted to the hospital, during treatment or even when discharged from the hospital, which is closely related to hospital care. The incidence of HM is still quite high and can increase morbidity and mortality among inpatient children. This study aims to determine the characteristics of in-hospital malnutrition cases in children undergoing treatment at Sanglah Hospital.

Methods: This study used a prospective cohort design using primary data obtained from interviews and anthropometry of 120 children hospitalized at Sanglah Hospital in the 2019-2020 period. HM was defined as a decrease in a Z-score of Weight/Height $(\mathrm{W} / \mathrm{H})>$ 0.5 Standard Deviation (SD) at the time of hospital discharge. Data were analyzed using SPSS version 20 for Windows.

Keywords: Hospital Malnutrition, Children, Characteristics.

Cite This Article: Hanzelina., Sidiartha, I.G.L., Pratiwi, I.G.A.P.E. 2021. Karakteristik malnutrisi rumah sakit pada pasien anak di RSUP Sanglah, Bali, Indonesia. Intisari Sains Medis 12(2): 666-671. Dol: 10.15562/ism.v12i2.1079

\section{ABSTRAK}

Latar Belakang: Malnutrisi rumah sakit (MRS) adalah malnutrisi yang didiagnosis saat dirawat di Rumah Sakit (RS) baik saat masuk RS, selama perawatan atau bahkan saat pasien keluar dari rumah sakit yang erat kaitannya dengan perawatan di RS. Kejadian MRS masih cukup tinggi dan dapat meningkatkan morbiditas dan mortalitas pada anak yang dirawat. Penelitian ini bertujuan untuk mengetahui karakteristik dari kasus MRS pada anak yang menjalani perawatan di RSUP Sanglah.

Metode: Studi ini menggunakan desain kohort prospektif dengan menggunakan data primer dari wawancara dan pemeriksaan antropometri terhadap 120 anak yang dirawat inap di RSUP Sanglah pada periode 2019-2020. MRS didefinisikan sebagai penurunan Z-score Berat Badan/Tinggi Badan (BB/TB) $\geq 0,5$ Standard Deviation (SD) pada saat keluar RS. Data
Results: The incidence of HM was $47.1 \%$, of which $54.0 \%$ of patients were female. The incidence of inhospital malnutrition was primarily found in patients aged 1-3 years $(50.0 \%)$ and $>5$ years $(42.0 \%)$. Approximately $64.0 \%$ of children with HM were malnourished before being admitted to the hospital and $14.0 \%$ got parenteral nutrition. It was found that $72 \%$ of children with HM had a hospital stay length of $>7$ days. More than half of children with HM (56.0\%) have parents with low levels of education (less than secondary education) and $58.0 \%$ have more than 3 siblings.

Conclusion: The incidence of hospital malnutrition is more often found in girls, age $>5$ years old, malnutrition before admitted, get parenteral nutrition, had parents with low education levels, number of siblings $>3$, had a single diagnosis and length of stay $>7$ days. dianalisis dengan SPSS versi 25 untuk Windows.

Hasil: Kejadian MRS ditemukan sebanyak $47,1 \%$ dengan $54,0 \%$ sampel berjenis kelamin perempuan. Insidens MRS paling banyak ditemukan pada pasien kelompok usia 1-3 tahun $(50,0 \%)$ dan $>5$ tahun (42,0\%). Sebanyak $64,0 \%$ anak dengan MRS sudah mengalami malnutrisi sebelum masuk RS dan 14,0\% mendapatkan nutrisi parenteral. Ditemukan bahwa $72,0 \%$ anak dengan MRS memiliki lama rawat di RS $>7$ hari. Lebih dari separuh anak dengan MRS $(56,0 \%)$ memiliki orang tua dengan tingkat pendidikan rendah ( $\leq$ SMP) dan 58,0\% memiliki jumlah saudara lebih dari $\geq 3$.

Kesimpulan: Insiden MRS lebih sering ditemukan pada anak perempuan, kelompok usia $>5$ tahun, malnutrisi sebelum masuk $\mathrm{RS}$, mendapatkan nutrisi parenteral, memiliki orang tua dengan tingkat 
pendidikan rendah, jumlah saudara kandung $\geq 3$, serta memiliki diagnosis tunggal serta lama rawat $\geq 7$ hari.

Kata kunci: Malnutrisi Rumah Sakit, Anak, Karakteristik.

Sitasi Artikel ini: Hanzelina., Sidiartha, I.G.L., Pratiwi, I.G.A.P.E. 2021. Karakteristik malnutrisi rumah sakit pada pasien anak di RSUP Sanglah, Bali, Indonesia. Intisari Sains Medis 12(2): 666-671. D0I: 10.15562/ism.v12i2.1079

\section{PENDAHULUAN}

Malnutrisi Rumah Sakit (MRS) adalah malnutrisi yang terjadi saat pasien dirawat di Rumah Sakit (RS) baik saat masuk RS, selama perawatan atau bahkan saat pasien keluar dari RS. ${ }^{1}$ Kejadian MRS berkaitan dengan dukungan nutrisi selama perawatan dan kurang optimalnya perhatian terhadap status nutrisi anak. ${ }^{1}$ Risiko malnutrisi pada anak selama perawatan di RS secara global didapatkan 85\%. Angka insiden MRS di negara maju terjadi sekitar $6,1 \%$ - 11,0\%, sedangkan di negara berkembang memiliki angka insiden yang lebih tinggi, yaitu 6,9\% hingga $53 \%$. $^{2}$ Penelitian mengenai MRS pada anak pernah dilakukan di RSUP Sanglah pada tahun 2007 dengan angka prevalensi sebesar 30,1\%. ${ }^{3}$ Risiko terjadinya MRS meningkat 3,69 kali pada anak yang dirawat lebih dari seminggu. ${ }^{4}$ Rocha GA et al., melaporkan penurunan berat badan pada $9,17 \%$ pasien dengan status nutrisi normal saat keluar dari rumah sakit. ${ }^{5}$

Beberapa studi sebelumnya mendefinisikan MRS sebagai terjadinya penurunan berat badan lebih dari $2 \%$ dalam seminggu atau lebih dari 5\% dalam sebulan atau lebih dari 7,5\% dalam 3 bulan atau lebih dari 10\% dalam 6 bulan. ${ }^{6,7}$ Kelemahan kriteria ini yaitu tidak mempertimbangkan tinggi badan (TB) pasien sehingga meningkatkan insidens MRS., ${ }^{2,3}$ Kriteria MRS menurut studi sebelumnya dibuat dengan mempertimbangkan TB anak, dimana dikatakan MRS bila terjadi penurunan $Z$ Score $\mathrm{BB} / \mathrm{TB} \geq 0,5 \mathrm{SD}$ pada saat pasien keluar RS dibandingkan dengan pada saat masuk RS. ${ }^{8,9}$

Perbedaan standar penentuan status nutrisi anak, definisi MRS, alat skrining pasien dengan risiko malnutrisi, maupun tata laksana nutrisi pada pasien rawat inap dapat menyebabkan tingginya insidens MRS. ${ }^{8}$ Kondisi ini menyebabkan bertambahnya lama rawat, penyembuhan yang lebih lama, peningkatan biaya perawatan, dan dapat meningkatkan angka mortalitas akibat adanya infeksi. Deteksi dini dan pencegahan terjadinya MRS penting untuk dilakukan.,10 Data mengenai karakteristik MRS pada anak masih sangat minim dan pada praktik sehari-hari masih didapatkan kejadian malnutrisi rumah sakit meskipun tatalaksana nutrisi pada anak yang dirawat di RS sudah dilakukan secara adekuat, sehingga dilakukan penelitian ini dengan tujuan untuk mengetahui insidens dan karakteristik malnutrisi rumah sakit yang terjadi pada anak.

\section{METODE}

Penelitian ini menggunakan rancangan penelitian kohort prospektif sejak bulan Mei 2019 hingga Mei 2020. Subjek pada penelitian ini adalah semua anak yang dirawat di ruang rawat inap anak kelas I, II dan III RSUP Sanglah di antara periode penelitian diseleksi untuk dapat diikutsertakan dalam penelitian. Kriteria inklusi antara lain 1) anak berusia 1 bulan sampai 18 tahun yang dirawat di ruang rawat inap anak kelas I, II dan III RSUP Sanglah, Denpasar, Bali; 2) orangtua/ wali setuju mengikutsertakan anak mereka dalam penelitian secara sukarela dengan menandatangani persetujuan setelah penjelasan (informed consent). Kriteria eksklusi adalah subjek yang selama perawatan pernah dirawat di Unit Perawatan Intensif Anak (UPIA), subjek meninggal dalam satu kali 24 jam pertama perawatan, anak dengan retensi cairan (edema anasarca dan ascites), hidrosefalus, anemia aplastik, penyakit keganasan yang mengenai sistem hemato onkologi, Acquired Immune Deficiency Syndrome (AIDS), Lupus Eritematosus Sistemik (LES), tuberkulosis, pasien dengan tumor padat, pasien dengan organomegali seperti hepatomegali dan splenomegali, pasien dengan riwayat kemoterapi, penggunaan steroid jangka panjang, overweight dan obesitas. Subjek yang pindah perawatan ke rumah sakit sebelum waktunya pulang sesuai dengan keputusan DPJP atau subjek yang pulang dari rumah sakit atas permintaan sendiri dinyatakan sebagai loss to follow up.

Pengambilan sampel dilakukan dengan cara consecutive sampling sampai jumlah subyek terpenuhi. Besar sampel dihitung berdasarkan insidens MRS sebelumnya sebesar 30\%, dengan penetapan presisi sebesar $15 \%$, dan tingkat kemaknaan $a<0,05$. Besar sampel minimal yang dibutuhkan adalah 120 sampel.

Diagnosis Malnutrisi Rumah Sakit (MRS) jika terjadi penurunan nilai $\mathrm{Z}$ score $\mathrm{BB} / \mathrm{TB} \geq 0,5 \mathrm{SD}$ antara $\mathrm{BB} / \mathrm{TB}$ saat masuk dan keluar RS. Status gizi saat masuk rumah sakit dinilai dengan menggunakan kurva WHO berdasarkan berat badan $(\mathrm{BB})$ terhadap panjang atau tinggi badan (PB/TB) untuk anak berusia $\leq 5$ tahun. Anak berusia lebih dari 5 tahun menggunakan kurva CDC dan diklasifikasikan berdasarkan klasifikasi waterlow dibagi menjadi (1) malnutrisi $(<90 \%)$ dan (2) tidak malnutrisi $(\geq 90 \%)$. Cara pemberian nutrisi adalah rute pemberian makan selama dalam perawatan di rumah sakit sesuai dengan keputusan DPJP. Data ini disajikan dalam skala kategorik nominal yaitu (1) oral, (2) enteral dan (3) parenteral. Usia adalah usia kronologis pada saat dirawat di rumah sakit dan disajikan dalam skala numerik. Jenis kelamin ditentukan berdasarkan penampakan fenotip dan data disajikan dalam skala nominal yaitu (1) perempuan dan (2) laki - laki. Kompleksitas penyakit adalah jumlah diagnosis penyakit yang diderita oleh subjek sesuai dengan keputusan DPJP yang tercatat dalam rekam medis subjek. Data disajikan dengan skala kategorik nominal yaitu (1) tunggal dan (2) multipel. Lama rawat ditentukan berdasarkan lamanya waktu yang dibutuhkan oleh subjek selama dirawat di rumah sakit sesuai dengan keputusan DPJP dan data disajikan 
dalam skala numerik. Pendidikan adalah pendidikan formal ibu dan dinyatakan sebagai data dengan skala kategorik ordinal (1) rendah, (2) tidak rendah. Status ekonomi merupakan suatu keadaan yang menggambarkan status keuangan dari orangtua yang diperoleh dalam satu bulan. Sosial ekonomi dibagi menjadi dua (sesuai dengan Upah Minimum Regional di Kota Denpasar) yaitu (1) rendah apabila pendapatan per bulan $<\mathrm{Rp} 2.363 .000,00$, (2) tidak rendah apabila pendapatan per bulan $>$ Rp 2.363.000,00. Jumlah saudara kandung dibagi menjadi tidak ada saudara kandung, memiliki saudara kandung $<3$ saudara dan memiliki saudara kandung $\geq 3$ saudara.

Penelitian ini menggunakan data primer dari wawancara dan pengukuran antropometri. Data yang terkumpul kemudian dianalisis menggunakan SPSS versi 25 untuk Windows.

\section{HASIL}

Penelitian dilakukan pada bulan Mei 2019 sampai Mei 2020 dengan total subjek 132 pasien selanjutnya dilakukan eksklusi sebanyak 7 pasien yang meninggal selama perawatan dan 5 pasien yang loss to follow up sehingga pasien yang ikut serta dalam penelitian adalah 120 pasien. Distribusi dan karakteristik umum subjek dapat dilihat di Tabel 1.

Pasien yang mengalami MRS sebanyak 50 pasien $(41,7 \%)$ dan 70 pasien $(59,3 \%)$ tidak mengalami MRS. Rerata penurunan berat badan selama perawatan di rumah sakit adalah 0,58 $\pm 0,2 \mathrm{~kg}$. Karakteristik pasien yang mengalami MRS dapat dilihat di Tabel 2.

\section{PEMBAHASAN}

Insidens MRS pada penelitian ini sebanyak $41,7 \%$. Hasil ini lebih tinggi dibandingkan penelitian sebelumnya dimana prevalens MRS berkisar antara 5\%-30,1\%. ${ }^{9-13} \mathrm{Kac}$ $\mathrm{G}$ et al., melaporkan perburukan status gizi selama perawatan di RS sebesar 5\% 27\%. ${ }^{9}$ Penelitian yang dilakukan di RSUP Dr Sardjito pada tahun 2016, menemukan bahwa proporsi MRS pada anak adalah $27 \% .^{12}$ Penelitian lainnya yang dilakukan di RSUD Wangaya, Bali pada tahun 2019 didapatkan 37\% anak mengalami MRS. ${ }^{13}$

Kejadian MRS di RSUP Sanglah

\section{Tabel 1. Karakteristik Umum Subjek Penelitian}

\begin{tabular}{|c|c|}
\hline Variabel & Jumlah $(\mathrm{N}=120)$ \\
\hline \multicolumn{2}{|l|}{ Jenis kelamin, n (\%) } \\
\hline Laki-Laki & $59(49,2)$ \\
\hline Perempuan & $61(51,8)$ \\
\hline \multicolumn{2}{|l|}{ Usia (Bulan), n (\%) } \\
\hline $1-36$ & $47(39,2)$ \\
\hline$>36-60$ & $12(10,0)$ \\
\hline$>60$ & $61(50,8)$ \\
\hline \multicolumn{2}{|l|}{ Malnutrisi saat masuk RS, n (\%) } \\
\hline Ringan & $22(18,3)$ \\
\hline Sedang & $19(15,8)$ \\
\hline Berat & $7(5,8)$ \\
\hline \multicolumn{2}{|l|}{ Cara pemberian nutrisi, n (\%) } \\
\hline Oral & $105(85,0)$ \\
\hline Enteral & $5(4,2)$ \\
\hline Parenteral & $10(8,3)$ \\
\hline \multicolumn{2}{|l|}{ Kompleksitas, n (\%) } \\
\hline Diagnosis multipel & $40(33,3)$ \\
\hline \multicolumn{2}{|l|}{ Lama rawat (Hari), n (\%) } \\
\hline$<7$ & $40(33,3)$ \\
\hline $7-14$ & $35(29,2)$ \\
\hline $15-21$ & $37(30,8)$ \\
\hline $22-30$ & $4(3,3)$ \\
\hline$>30$ & $4(3,3)$ \\
\hline \multicolumn{2}{|l|}{ Pendidikan Ibu, n (\%) } \\
\hline Rendah & $35(39,2)$ \\
\hline \multicolumn{2}{|l|}{ Jumlah saudara kandung, n (\%) } \\
\hline$\geq 3$ saudara & $50(41,7)$ \\
\hline \multicolumn{2}{|l|}{ Penghasilan Orang Tua, n (\%) } \\
\hline Rendah & $31(25,8)$ \\
\hline \multicolumn{2}{|c|}{ Antropometri Berat Badan $(\mathrm{BB})(\mathrm{Kg})($ rerata $\pm \mathrm{SB})$} \\
\hline Sebelum perawatan & $21,22 \pm 16,80$ \\
\hline Setelah perawatan & $20,64 \pm 16,60$ \\
\hline
\end{tabular}

meningkat dalam kurun waktu 13 tahun, dimana data sebelumnya pada tahun 2006-2007 melaporkan proporsi kejadian MRS di RSUP Sanglah sebesar 30,1\%. ${ }^{4}$ Hasil pada penelitian ini serupa dengan penelitian yang dilakukan di Brazil pada 203 anak yang dirawat di RS tersier di tahun 2006 dimana kejadian MRS dilaporkan yang cukup tinggi yaitu sebesar 51,6\%. ${ }^{5}$ Angka kejadian MRS yang tinggi pada penelitian ini dapat disebabkan oleh jumlah subjek yang terlibat lebih sedikit dibandingkan dengan penelitian 13 tahun silam yang menggunakan sampel 2 kali lipat dari jumlah total subjek pada studi ini, sehingga faktor determinator yang lebih kecil mungkin menyebabkan angka insidens MRS yang jauh lebih tinggi pada penelitian ini.

Penelitian ini menemukan tidak ada perbedaan karakteristik yang signifikan antara kelompok MRS dibandingkan dengan kelompok non-MRS. Insidens
MRS lebih tinggi pada perempuan dibandingkan dengan lelaki. Hasil serupa ditemukan pada penelitian sebelumnya dimana dilaporkan insidens MRS pada perempuan lebih tinggi dibandingkan dengan laki-laki $(51,2 \%$ vs $48,8 \%) .{ }^{14}$ Hasil temuan ini berbanding terbalik dengan studi sebelumnya dimana anak laki-laki lebih banyak mengalami MRS yang disebabkan oleh lebih tingginya laju metabolik basal pada anak laki-laki dan cadangan energi lemak lebih rendah pada anak lelaki dibandingkan dengan anak perempuan. ${ }^{10,14}$ Insidens MRS pada perempuan dapat disebabkan karena lebih tingginya prevalensi malnutrisi sebelum masuk RS pada perempuan dibandingkan lelaki terutama pada negara Asia. Hal ini disebabkan oleh karena adanya prioritas orang tua terhadap anak lakilaki dibandingkan dengan perempuan yang menyebabkan intake kalori pada anak perempuan Asia cenderung lebih 
Tabel 2. Karakteristik subjek yang mengalami Malnutrisi Rumah Sakit (MRS) di RSUP Sanglah Periode 2019-2020

\begin{tabular}{|c|c|c|}
\hline \multirow{2}{*}{ Variabel } & \multicolumn{2}{|c|}{ Kelompok Penelitian ( $\mathrm{N}=120)$} \\
\hline & MRS $(\mathrm{N}=50)$ & Non-MRS $(\mathrm{N}=70)$ \\
\hline \multicolumn{3}{|l|}{ Jenis kelamin, $\mathrm{n}(\%)$} \\
\hline Lelaki & $23(46,0)$ & $36(51,4)$ \\
\hline Perempuan & $27(54,0)$ & $34(48,6)$ \\
\hline \multicolumn{3}{|l|}{ Usia, n (\%) } \\
\hline $1-36$ bulan & $25(50,0)$ & $22(31,4)$ \\
\hline$>36-60$ bulan & $4(8,0)$ & $8(11,4)$ \\
\hline$>60$ bulan & $21(42,0)$ & $40(57,2)$ \\
\hline \multicolumn{3}{|c|}{ Malnutrisi saat masuk RS, n (\%) } \\
\hline $\mathrm{Ya}$ & $32(64,0)$ & $16(22,9)$ \\
\hline Tidak & $18(36,0)$ & $54(77,1)$ \\
\hline \multicolumn{3}{|c|}{ Cara pemberian nutrisi, n (\%) } \\
\hline Enteral & $3(6,0)$ & $2(2,9)$ \\
\hline Parenteral & $7(14,0)$ & $3(4,3)$ \\
\hline \multicolumn{3}{|l|}{ Diagnosis, $\mathrm{n}(\%)$} \\
\hline Multipel & $21(42,0)$ & $19(27,1)$ \\
\hline Tunggal & $29(58,0)$ & $51(72,9)$ \\
\hline \multicolumn{3}{|l|}{ Lama rawat (Hari), n (\%) } \\
\hline$<7$ & $14(28,0)$ & $26(37,1)$ \\
\hline$\geq 7$ & $36(72,0)$ & $44(62,9)$ \\
\hline \multicolumn{3}{|l|}{ Pendidikan ibu, n (\%) } \\
\hline Rendah & $28(56,0)$ & $7(10,0)$ \\
\hline Tinggi & $22(44,0)$ & $63(90,0)$ \\
\hline \multicolumn{3}{|c|}{ Jumlah saudara kandung, n (\%) } \\
\hline$<3$ & $21(42,0)$ & $49(70,0)$ \\
\hline$\geq 3$ & $29(58,0)$ & $21(30,0)$ \\
\hline \multicolumn{3}{|c|}{ Penghasilan Orang Tua, n (\%) } \\
\hline Rendah & $13(36,0)$ & $18(25,7)$ \\
\hline Tidak rendah & $37(74,0)$ & $52(74,3)$ \\
\hline
\end{tabular}

rendah. ${ }^{15}$

Insidens MRS pada penelitian ini lebih tinggi pada kelompok usia 1-3 tahun dan diatas 5 tahun. Hasil ini serupa dengan penelitian sebelumnya yang dilakukan di RS tersier di Kenya dimana kejadian MRS lebih sering ditemukan pada anak berusia 1-2 tahun (71,6\%) diikuti oleh usia 2-5 tahun $(62,2 \%)$ dan 5-12 tahun $(59,6 \%) .{ }^{16}$ Anak berusia 1-3 tahun lebih rentan terhadap kejadian MRS dikarenakan kebutuhan kalori per kilogram berat badan yang lebih besar serta metabolisme basal yang lebih cepat dibandingkan dengan usia yang lebih tua. Anak dengan usia di atas 5 tahun juga berisiko terjadi MRS dikarenakan pada usia tersebut anak lebih dapat toleran terhadap asupan nutrisi yang tidak memadai hingga 7 hari, sehingga seringkali hanya memperoleh intake yang sedikit di rumah sakit tanpa diketahui oleh wali mereka. ${ }^{5}$

Kondisi lain yang dapat memengaruhi anak dengan malnutrisi berat saat masuk RS memiliki jumlah saudara kandung lebih dari atau sama dengan $2 .{ }^{18}$

Penelitian ini juga menemukan lebih dari separuh anak dengan MRS memiliki orangtua dengan tingkat pendidikan yang rendah. Tingkat pendidikan, sama halnya dengan jumlah saudara tidak memengaruhi MRS secara langsung, namun dapat memberikan dampak terhadap status gizi yang lebih buruk pada awal masuk RS sehingga meningkatkan risiko terjadinya MRS. ${ }^{5,12}$ Jahanihasemi $\mathrm{H}$ et al., dalam penelitiannya melaporkan bahwa $49,12 \%$ anak dengan malnutrisi berat memiliki orang tua dengan pendidikan primer, dan sebanyak $32,01 \%$ tidak menyelesaikan pendidikan sekunder $(\mathrm{p}<0,001){ }^{19}$ Penelitian tersebut menemukan tingkat pendidikan ibu secara bermakna lebih memengaruhi status nutrisi anak dibandingkan dengan tingkat pendidikan ayah dikarenakan ibu menghabiskan waktu lebih banyak dalam hal mengurus kebutuhan makan anak. ${ }^{19}$ Tingkat pendidikan akan memengaruhi pengetahuan orang tua akan kecukupan gizi anak dan dapat berkorelasi dengan tingkat pendapatan orang tua. ${ }^{19-21}$

Insidens MRS pada pasien yang sudah terdiagnosis dengan malnutrisi sebelum masuk RS lebih tinggi dibandingkan dengan yang tidak terdiagnosis malnutrisi. Hasil ini sejalan dengan hasil yang ditunjukkan pada penelitian yang dilakukan Budiputri GL et al., dimana insidens anak yang mengalami MRS dengan status nutrisi gizi kurang saat masuk RS (BB/TB <-2SD atau $<90 \%$ berdasarkan kurva CDC) sebesar 36,6\% dan memiliki risiko 1,96 kali untuk mengalami MRS $(95 \% \mathrm{IK}=1,25-3,09) .{ }^{13}$ Anak dengan gizi kurang cenderung mengalami lama rawat inap yang lebih panjang akibat dari kurangnya energi untuk memenuhi kebutuhan tubuh selama proses penyembuhan. Anak dengan gizi kurang saat masuk RS lebih rentan untuk mengalami perburukan status gizi dan MRS pada masa perawatan. ${ }^{5,12}$

Penelitian ini menemukan insidens MRS lebih tinggi pada pasien yang memiliki diagnosis tunggal dibandingkan dengan diagnosis multipel. Hasil ini berbeda dengan penelitian sebelumnya yang menunjukkan bahwa proporsi anak 
dengan diagnosis multipel sebesar 31,4\% dan memiliki risiko 2,35 kali lebih besar untuk menjadi MRS dibandingkan dengan yangmemilikisatudiagnosis $(95 \% \mathrm{CI}=1,23$ 4,48). Hal ini terjadi dikarenakan pasien dengan diagnosis multipel cenderung mengalami pelepasan marker inflamasi yang lebih tinggi dalam tubuhnya yang menyebabkan terganggunya status nutrisi mereka. Diagnosis multipel juga memiliki keterkaitan dengan lama perawatan di RS yang lebih lama. ${ }^{11}$ Insidens MRS pada kelompok diagnosis tunggal yang lebih tinggi pada penelitian ini mungkin dapat disebabkan jumlah diagnosis tidak selamanya berbanding lurus dengan kompleksitas penyakit dan penelitian ini didapatkan dua diagnosis primer pada pasien yang mengalami MRS adalah yang mengenai sistem organ respirasi sebanyak 38\% dan sistem gastrointestinal sebesar 20\%. Data dari WHO menemukan penyakit respirasi terutama Infeksi Saluran Pernapasan Akut (ISPA) merupakan penyebab utama morbiditas dan mortalitas di dunia. Penelitian di Afrika juga mendapatkan risiko MdRS terutama adalah pada pasien-pasien dengan infeksi di saluran respirasi. ${ }^{22}$ Perbedaan hasil temuan pada penelitian ini harus diteliti secara lebih lanjut.

Insidens MRS pada pasien yang mendapatkan nutrisi secara parenteral lebih tinggi dibandingkan secara enteral yaitu $14 \%$ dan $6 \%$ pada penelitian ini. Hasil serupa juga ditemukan pada penelitian sebelumnya dimana pada pasien yang mengalami MRS mendapatkan nutrisi secara parenteral sebanyak $8,4 \%$ dan secara enteral sebanyak $7,6 \%{ }^{23}$ Komplikasi yang dapat ditimbulkan akibat cara pemberian nutrisi adalah risiko infeksi. Pemberian nutrisi secara enteral dapat menurunkan infeksi sebesar $0,64 \%$ dibanding secara parenteral. Penelitian lain menemukan bahwa kasus infeksi lebih banyak terjadi pada pasien yang diberi nutrisi secara parenteral dibandingkan enteral. ${ }^{24,25}$ Risiko infeksi ini juga berperan dalam lama rawat inap pasien yang lebih lama sehingga berisiko terjadinya MRS.

Insidens MRS pada pasien yang dirawat selama $\geq 7$ hari lebih tinggi dibandingkan dengan yang dirawat $<7$ hari. Hasil ini serupa dengan penelitian sebelumnya di RSUP Sanglah pada tahun 2010 menunjukkan insidens MRS pada pasien yang dirawat selama $\geq 7$ hari sebesar $31,2 \%$ dibandingkan dengan yang dirawat $<7$ hari sebesar $10,7 \%{ }^{4}$ Penelitian terdahulu juga menunjukkan bahwa semakin lama perawatan di rumah sakit akan berhubungan dengan penurunan berat badan, dimana risiko penurunan akan meningkat dari 2,43 kali $(95 \%$ CI $1,46-$ 4,03 ) pada perawatan 3-5 hari menjadi 4,67 kali $(95 \% \mathrm{CI}=1,34-16,24)$ pada perawatan lebih dari seminggu. ${ }^{13}$ Penelitian lainnya juga menemukan bahwa lama rawat lebih dari seminggu meningkatkan risiko MRS sebesar 8,219 kali dibandingkan dengan yang dirawat kurang dari seminggu $(95 \% \mathrm{CI}=1,643-41,098) .{ }^{12} \quad$ Penelitian yang dilakukan di Turki menunjukkan adanya perbedaan insidens MRS pada pasien yang dirawat lebih dari 3 hari dibandingkan dengan yang mendapatkan perawatan 1-2 hari di RS $(\mathrm{p}=0,047) .{ }^{11}$ Lama perawatan dikaitkan dengan paparan terhadap infeksi nosokomial yang dapat menyebabkan pelepasan mediator inflamasi serta penggunaan energi yang disebabkan oleh aktivitas patogen dalam tubuh yang menyebabkan perburukan status gizi. ${ }^{12,16}$ Anak seringkali tidak berminat dalam mengkonsumsi makanan yang disediakan rumah sakit, sehingga semakin lama perawatan tentunya akan menyebabkan semakin menurunnya intake kalori anak. ${ }^{5,11}$ Perawatan lama di rumah sakit juga dikaitkan dengan adanya prosedur invasif yang mungkin dijalani anak, dimana prosedur invasif seperti pembedahan membutuhkan interupsi asupan kalori seperti berpuasa maupun pantangan makan. ${ }^{5}$ Studi ini hanya menggunakan satu senter sebagai sumber data sehingga hasil studi mungkin saja kurang representatif terhadap populasi sesungguhnya.

\section{SIMPULAN}

Kejadian MRS di RSUP Sanglah periode Mei 2019 - Mei 2020 adalah sebesar 41,7\%, Insidens MRS lebih sering ditemukan pada anak perempuan, kelompok usia lebih dari 5 tahun, malnutrisi sebelum masuk RS, mendapatkan nutrisi secara parenteral, memiliki orang tua dengan tingkat pendidikan rendah, jumlah saudara kandung $\geq 3$, memiliki diagnosis tunggal serta lama rawat $\geq 7$ hari. Studi lebih lanjut dengan data dari beragam center dapat dilakukan untuk menentukan faktor risiko dari MRS.

\section{KONFLIK KEPENTINGAN}

Tidak terdapat konflik kepentingan dalam penulisan laporan penelitian ini.

\section{ETIKA PENELITIAN}

Penelitian ini telah mendapatkan kelaikan etik (Ethical Clearance) dari Komisi Etik Penelitian Fakultas Kedokteran Universitas Udayana, RSUP Sanglah, Bali, Indonesia dengan nomor 2361/UN14.2.2.VII.14/ LP/2019 sebelum penelitian berjalan.

\section{PENDANAAN}

Tidak ada.

\section{KONTRIBUSI PENULIS}

Seluruh penulis memiliki kontribusi yang sama dalam penulisan laporan penelitian ini baik dari tahap penyusunan kerangka konsep, pengumpulan data, analisis data, hingga interpretasi hasil penelitian dalam bentuk publikasi ilmiah.

\section{DAFTAR PUSTAKA}

1. Campanozzi A, Russo M, Catucci A, et al. Hospital-acquired malnutrition in children with mild clinical conditions. Nutrition. 2009;25(5):540-547.

2. Rinninella E, Cintoni $M$, De Lorenzo A, Addolorato G, Vassallo G, Moroni R, et al. Risk, prevalence, and impact of hospital malnutrition in a Tertiary Care Referral University Hospital: a cross-sectional study. Intern Emerg Med. 2018;13(5):689-697.

3. Sidiartha IGL. Malnutrisi rumah sakit pada anak di rumah sakit umum pusat Sanglah, Denpasar. Dalam: Kumpulan Naskah Lengkap PIT IV IKA Medan 2010. Medan: Ikatan Dokter Anak Indonesia. 2010:56-65.

4. Sidiartha IGL. Insidens Malnutrisi Rumah Sakit Pada Anak Di Rumah Sakit Umum Pusat Sanglah Denpasar. Sari Pediatri. 2008;9(6):381385.

5. Rocha GA, Rocha EJ, Martins CV. The effects of hospitalization on the nutritional status of children. J Pediatr (Rio J). 2006;82(1):70-74.

6. Waitzberg DL, Correia MI. Nutritional assessment in the hospitalized patient. Curr Opin Clin Nutr Metab Care. 2003;6(5):531-538.

7. Oken E, Lightdale JR. Updates in pediatric nutrition. Curr Opin Pediatr. 2000;12(3):282290.

8. Mehta NM, Corkins MR, Lyman B, Malone A, Goday PS, Carney LN, et al. Defining pediatric malnutrition: a paradigm shift toward etiology- 
related definitions. JPEN J Parenter Enteral Nutr. 2013;37(4):460-481.

9. Kac G, Camacho-Dias P, Silva-Coutinho D, Silveira-Lopes R, Marins VV, Pinheiro AB. Length of stay is associated with incidence of in-hospital malnutrition in a group of lowincome Brazilian children. Salud Publica Mex. 2000;42(5):407-412.

10. Sidiartha IGL, Pratiwi IGAPE. Implementation of STRONGkids in identify risk of malnutrition in government hospital. Int $\mathrm{J}$ Heal Sci. 2018;2(2):18-24.

11. Beser OF, Cokugras FC, Erkan T, Kutlu T, Yagci RV; TUHAMAR Study Group. Evaluation of malnutrition development risk in hospitalized children. Nutrition. 2018;48:40-47.

12. Maryani E, Prawirohartono EP, Nugroho S. Faktor Prediktor Malnutrisi Rumah Sakit pada Anak. Sari Pediatri. 2017;18(4):278-284.

13. Budiputri GL, Suryawan IWB, Dewi MR. Analisis faktor - faktor yang mempengaruhi kejadian Malnutrisi Rumah Sakit (MRS) pada pasien anak di Bangsal Kaswari, RSUD Wangaya, Bali, Indonesia. Intisari Sains Medis. 2020;11(2):680-685.

14. Miriawati, Irawan R, Hidayat B, Widjaya NA, Hanindita MH. Risk Factor of Hospital Malnutrition After Pediatric Nutrition Care Management. Heal Notions. 2021;5(1):23-28.
15. $\mathrm{Wu} \mathrm{BN}, \mathrm{O}$ 'Sullivan AJ. Sex differences in energy metabolism need to be considered with lifestyle modifications in humans. J Nutr Metab. 2011;2011:391809.

16. Khan T, Khan REA, Raza MA. Gender Analysis of Malnutrition: A Case Study of School-Going Children in Bahawalpur. Asian Dev Policy Rev. 2015;3(2):29-48.

17. Quadros DRS, Kamenwa R, Akech S, Macharia WM. Hospital-acquired malnutrition in children at a tertiary care hospital. South African J Clin Nutr. 2018;31(1):8-13.

18. de Oliveira Meller F, Assunção MC, Schäfer AA, de Mola CL, Barros AJ, Dahly DL, et al. The influence of birth order and number of siblings on adolescent body composition: evidence from a Brazilian birth cohort study. Br J Nutr. 2015;114(1):118-25.

19. Jahanihashemi H, Noroozi M, Zavoshy R, Afkhamrezaei A, Jalilolghadr S, Esmailzadehha N. Malnutrition and birth related determinants among children in Qazvin, Iran. Eur J Public Health. 2017;27(3):559-562.

20. Vollmer S, Bommer C, Krishna A, Harttgen K, Subramanian SV. The association of parental education with childhood undernutrition in low- and middle-income countries: comparing the role of paternal and maternal education. Int J Epidemiol. 2017;46(1):312-323.
21. Khattak UK, Iqbal SP, Ghazanfar H. The Role of Parents' Literacy in Malnutrition of Children Under the Age of Five Years in a Semi-Urban Community of Pakistan: A Case-Control Study. Cureus. 2017;9(6):e1316.

22. Blaauw R, Achar E, Dolman RC, Harbron J, Moens M, Munyi F, Nyatefe D, Visser J. The Problem of Hospital Malnutrition in the African Continent. Nutrients. 2019;11(9):2028.

23. Abdelhadi RA, Bouma S, Bairdain S, Wolff J, Legro A, Plogsted S, et al. Characteristics of Hospitalized Children With a Diagnosis of Malnutrition: United States, 2010. JPEN J Parenter Enteral Nutr. 2016;40(5):623-635.

24. Casaer MP, Mesotten D, Hermans G, Wouters PJ, Schetz M, Meyfroidt G, et al. Early versus late parenteral nutrition in critically ill adults. $\mathrm{N}$ Engl J Med. 2011;365(6):506-517.

25. Ziegler TR. Parenteral nutrition in the critically ill patient. N Engl J Med. 2009;361(11):10881097.

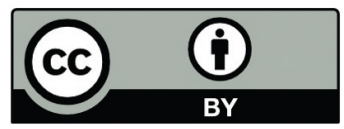

This work is licensed under a Creative Commons Attribution 